\title{
Interstitial deletion of the long arm of chromosome 2 with normal levels of isocitrate dehydrogenase
}

I A GLASS*†, C A SWINDLEHURST*, D A AITKEN*, W MCCREA , AND E BOYD*

${ }^{*}$ Duncan Guthrie Institute of Medical Genetics, and †Department of Child Health, Royal Hospital for Sick Children, Yorkhill, Glasgow G3 8SJ; and $¥$ Royal Scottish National Hospital, Larbert, Stirlingshire.

SUMMARY We report a 16 year old boy with the abnormal karyotype 46,XY, $\operatorname{del}(2)(\mathrm{q} 32.2 \mathrm{q} 33.1)$ who has mental retardation, microcephaly, epilepsy, craniofacial dysmorphism, distinctive scalloped skin pigmentation, and normal levels of isocitrate dehydrogenase.

Over 20 persons with interstitial deletions of the long arm of chromosome 2 have been described. ${ }^{1-3}$

Received for publication 14 March 1988. Accepted for publication 25 April 1988.

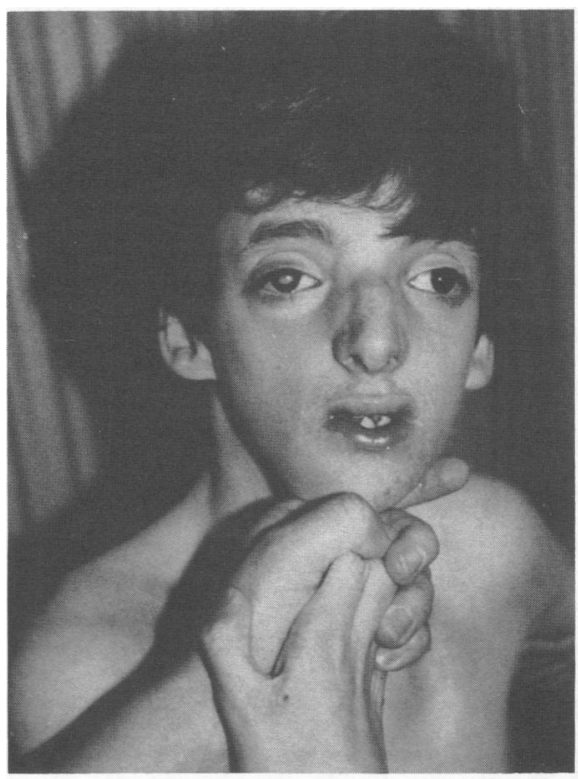

We report a further patient with an interstitial deletion with breakpoints $\operatorname{del}(2)(\mathrm{q} 32.2 \mathrm{q} 33.1)$ which have not previously been reported, who has distinctive clinical features including an unusual pattern of skin pigmentation. We compare his cytogenetic and clinical findings with those of eight previously reported cases in the largest subgroup of $2 q$ deletions: $\operatorname{del}(2)(\mathrm{q} 31 \mathrm{q} 33)$. $^{2-8}$

\section{Case report}

The proband is the third child of healthy, unrelated parents, the mother being 23 years at delivery. The pregnancy was normal until 32 weeks of gestation

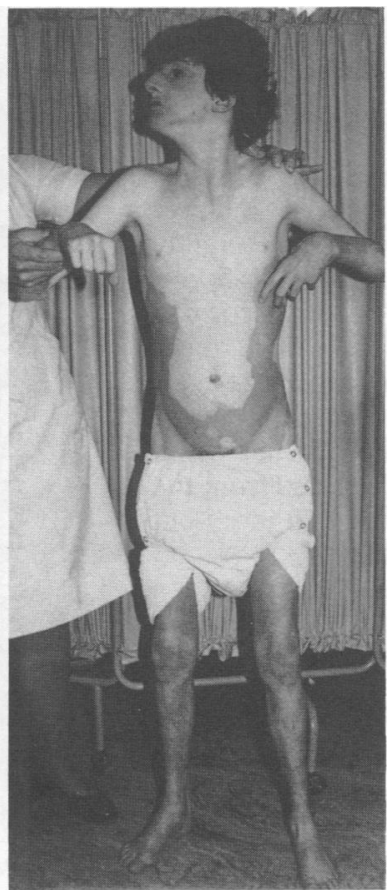

FIG 1 The proband aged 16 years. 

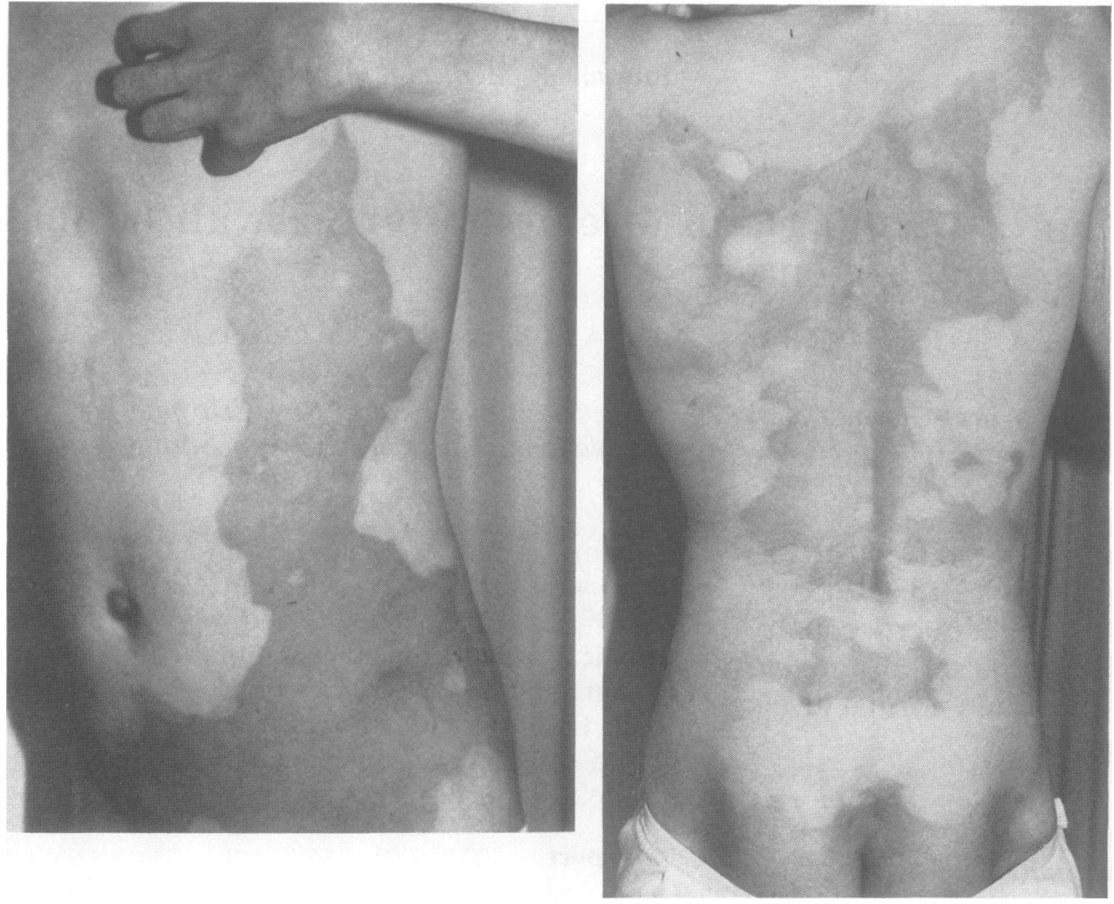

FIG 2 The proband's distinctive skin pigmentation.

when premature delivery occurred following an antepartum haemorrhage. The birth weight was 2070 g. Global developmental retardation and epilepsy were apparent from early childhood and ultimately resulted in his admission to an institution for the mentally handicapped. Evaluation at 16 years showed mental retardation with no comprehensible speech and total dependency, microcephaly (OFC $47 \mathrm{~cm},-5.3 \mathrm{SD}$ ), short stature $(149.5 \mathrm{~cm}$, $-3 \cdot 2 \mathrm{SD}$ ), a large beaked nose, bilateral corneal ectasia, divergent strabismus, bilateral ptosis, and a cleft palate (fig 1). He has a striking pattern of scalloped skin pigmentation, present from birth, which is approximately symmetrical on the trunk and proximal limbs and clearly demarcated from the normal skin (fig 2). His gait was slow and jerky but there were no other neurological signs.

An EEG showed diffuse abnormalities on an irregular polyrhythmic background.

A G banded karyotype of peripheral lymphocytes showed an interstitial deletion of the long arm of chromosome 2: del(2)(q32.2q33.1) (fig 3). Skin fibroblasts from both normal skin and pigmented skin showed the same karotype: 46,XY $\operatorname{del}(2)(q 32.2 q 33.1)$. The parents were unavailable for study.

Assay of the activity of the soluble form of isocitrate dehydrogenase (ICD-S, E.C.1.42) activity in red cells from the index case gave normal activity $(1.13 \mathrm{IU} / \mathrm{g} \mathrm{Hb}$, mean of 18 controls 0.93 $\mathrm{IU} / \mathrm{g} \mathrm{Hb}, \mathrm{SD} \mathbf{0 \cdot 2 8 )}$.

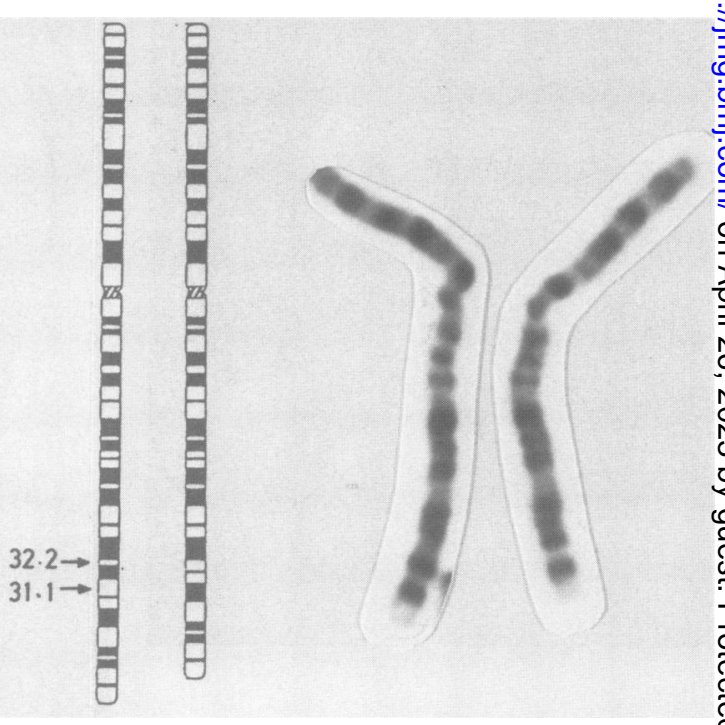

FIG 3 Idiogram and $G$ banded chromosome 2 of the proband indicating the breakpoints of the deletion. 


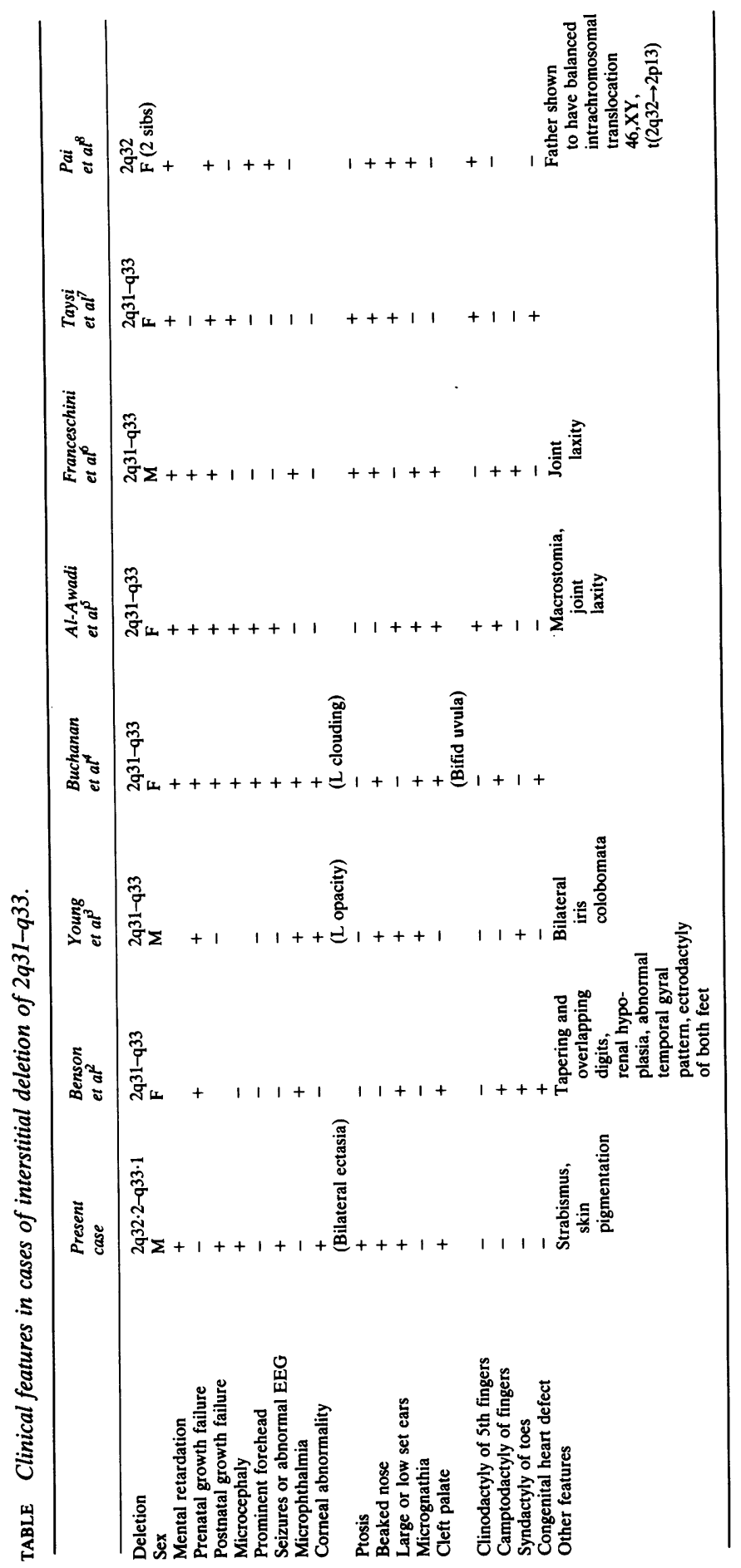




\section{Discussion}

The most frequently reported interstitial deletion of $2 \mathrm{q}$ involves the segments $\operatorname{del}(2)(\mathrm{q} 31 \mathrm{q} 33)$ and the clinical features of the other eight reported cases are outlined in the table. It is apparent that in addition to the general features shared with other $2 \mathrm{q}$ deletions (mental retardation, microcephaly, growth failure, and congenital heart defects),${ }^{1-3}$ more specific features of $\operatorname{del}(2)$ (q31q33) deletions, as suggested by Schinzel, ${ }^{9}$ include microphthalmia, corneal anomalies, ptosis, a beaked nose, micrognathia, cleft palate, large or low set ears, clinodactyly of the fifth finger, camptodactyly of the fingers, and syndactyly of the toes.

The present case shares some of the features of this subgroup of $2 \mathrm{q}$ deletions but he also shows distinctive skin pigmentation. The distribution of the skin abnormality did not follow Blaschko's lines and we found no evidence of chromosomal mosaicism by demonstrating the identical karyotypes in the fibroblasts derived from the pigmented and nonpigmented skin. The skin pigmentation may be related to the breakpoints of this deletion allowing expression of an otherwise suppressed gene, or it may represent a coincidental abnormality; further assignment of gene loci to $2 \mathrm{q} 31-\mathrm{q} 33$ may resolve this question.

The structural gene for the soluble form of isocitrate dehydrogenase (ICD-S, E.C.1.42) has been previously mapped to $2 \mathrm{q} 33.3$ by somatic cell hybridisation and gene dosage studies. ${ }^{10}$ The presence of normal levels of ICD-S in the proband suggested that the deletion breakpoint in band $\mathrm{q} 33 \overrightarrow{\mathrm{F}}$ lies proximal to the ICD-S locus.

\section{References}

${ }^{1}$ Lucas J, Faivre J, Le Mee F, Hubert S, Pluquailec K, Picard F De novo interstitial deletion: 46,XX,del(2)(q14q21) and premature craniosynostosis. Ann Genet (Paris) 1987;30:33-8.

2 Benson K, Gordon M, Wassman ER, Chung T. Interstitial deletion of the long arm of chromosome 2 in a malformed infan $P$ with karyotype 46,XX, del(2)(q31q33). Am J Med Genet 1986;25:405-11.

3 Young RS, Shapiro SD, Hansen KL, Hine LK, Rainosek DR? Guerra FA. Deletion 2q: two new cases with karyotypes 46,XY,del(2)(q31q33) and 46,XX,del(2)(q36). J Med Gene? 1983;20:199-202.

4 Buchanan PD, Rhodes RL, Stevenson CE. Interstitial deletion 2q31 $\rightarrow \mathrm{q} 33$. Am J Med Genet 1983;15:121-6.

5 Al-Awadi SA, Farag TI, Naguib K, et al. Interstitial deletion of the long arm of chromosome 2: $\operatorname{del}(2)(\mathrm{q} 31 \mathrm{q} 33)$. J Med Geneb 1983;20:464-5.

6 Franceschini P, Silengo MC, Davi G, Bianco R, Biagoli M.Interstitial deletion of the long arm of chromosome 2 (q31q33) in a girl with multiple anomalies and mental retardation. Hum Genet 1983;64:98.

7 Taysi K, Dengler DR, Jones LA, Heersma JR. Interstitia deletion of the long arm of chromosome 2: case report ank review of the literature. Ann Genet (Paris) 1981;24:245-7.

8 Pai GS, Rogers JF, Sommer A. Identical multiple congenitabo anomalies/mental retardation (MCA/MR) syndrome due to $\operatorname{del}(2)(\mathrm{q} 32)$ in two sisters with intrachromosomal insertional translocation in their father. Am J Med Genet 1983;14:189-95.

9 Schinzel A. Catalogue of unbalanced chromosome aberrations in man. Berlin: Walter de Gruyter, 1984:117.

10 Narahara K, Kimura S, Kikkawa K, et al. Probable assignmen of soluble isocitrate dehydrogenase (IDH1) to 2q33.3. HumD Genet 1985;71:37-40.

Correspondence and requests for reprints to Dr I A $\overline{\vec{\rho}}$ Glass, Duncan Guthrie Institute of Medica? Genetics, Yorkhill, Glasgow G3 8SJ.

\title{
A terminal deletion (14)(q31.1) in a child with microcephaly, narrow palate, gingival hypertrophy, protuberant ears, and mild mental retardation
}

\author{
FU-SUN YEN, PHILIP E PODRUCH, AND BERNARD WEISSKOPF \\ Child Evaluation Center, Department of Pediatrics, University of Louisville School of Medicine, Louisville, \\ Kentucky, USA.
}

SUMMARY A female child with a terminal deletion on the long arm of chromosome 14, $46, \mathrm{XX}, \operatorname{del}(14)(\mathrm{q} 31.1)$, presented with microcephaly, narrow palate, gingival hypertrophy, protuberant ears, and a small haemangioma on the back. She was mildly mentally retarded. Only a few patients with a partial

Received for publication 14 March 1988.

Revised version accepted for publication 8 June 1988 deletion of $14 q(14 q-)$ have been reported without consistent clinical findings. Although aO clinical syndrome associated with ring chromo-o some 14, r(14), has been established, no distinct pattern has been so far reported in ${ }^{+}$ $14 \mathrm{q}-$.

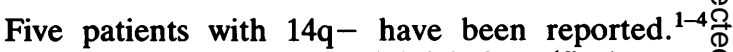
Three patients had interstitial deletions (fig 1, cases $\varrho$ 1,2 , and 3 ). One patient had a terminal deletion (fig? 